\title{
An IoT solution for prediction and Indication of probable region of fall of heavyweights lifted by Cranes in Industries
}

\author{
J Anudeep ${ }^{1}$, Shriram K Vasudevan ${ }^{2}$, Papini Balasai ${ }^{3}$, AK Sumesh ${ }^{4}$ \\ ${ }^{1}$ Dept. of Electronics and Communication Engineering, Amrita School of Engineering, Coimbatore, Amrita \\ Vishwa Vidyapeetham, India. anudeep.j06@gmail.com \\ ${ }^{2}$ Dept. of Computer Science and Engineering, Amrita School of Engineering, Coimbatore, Amrita Vishwa \\ Vidyapeetham, India. kv_shriram@cb.amrita.edu \\ ${ }^{3}$ Dept. of Electronics and Communication Engineering, Amrita School of Engineering, Coimbatore, Amrita \\ Vishwa Vidyapeetham. balasaipapini27@gmail.com \\ ${ }^{4}$ Dept. of Computer Science and Engineering, Amrita School of Engineering, Coimbatore, Amrita Vishwa \\ Vidyapeetham, India. ak_sumesh@cb.amrita.edu
}

\begin{abstract}
Deaths due to unnoticed fall of heavyweights lifted by cranes is an industrial problem. During the lift of heavy objects, there are cases where the hanging weight gets cut off and falls on the faraway workers. Many such incidents have been reported in the past and have claimed a lot of valuable lives. Some of such incidents have resulted in the death of many and some have given deep and strong injuries to the industry workers. To prevent such deaths or accidents, we developed a system using sensors \& IoT which can predict and indicate the danger zone inside which there is a probable chance of fall of the hanging weight. With this intimation, workers do not enter the danger zone while heavyweight is being lifted by the cranes thereby avoiding the injuries or damages.
\end{abstract}

Key words : Heavy weights, Cranes, Industries, IoT, danger area prediction, laser Indication.

\section{INTRODUCTION}

Cranes are the heavy machines equipped with pulleys and cables mostly used for moving, lifting and transportation of heavy objects. These are used in the construction industry, manufacturing industry, automobile industry and in many industries. Even though cranes are used in many places, necessary precautions are not taken in most of the situations while lifting heavy objects. According to the analysis done by National Institute for Occupational Safety and Health (NIOSH) on the fatal deaths of workers due to crane-related accidents, the deaths due to fall of heavyweights from cranes constitute to more than $40 \%$.
Table 1: Events resulting in mobile crane-related occupational injury deaths: United States [1]

\begin{tabular}{|l|c|c|}
\hline Issue & Deaths & $\begin{array}{l}\text { Percentag } \\
\text { e }\end{array}$ \\
\hline $\begin{array}{l}\text { Struck by falling or swinging object } \\
\text { (e.g., crane part or hoisted 290 40.3 } \\
\text { load) }\end{array}$ & 290 & 40.3 \\
\hline $\begin{array}{l}\text { Contact with electrical current (e.g., } \\
\text { overhead power lines) }\end{array}$ & 173 & 24.1 \\
\hline Fall from crane structure or cab & 88 & 12.2 \\
\hline $\begin{array}{l}\text { Transportation (e.g., moving crane } \\
\text { from site to site) }\end{array}$ & 76 & 10.6 \\
\hline Caught in crane moving parts & 73 & 10.2 \\
\hline Other & 19 & 2.6 \\
\hline
\end{tabular}

On referring the Table. 1, one can understand the impact even in the developed nations like the United States of America. Even in 2008 in the United States alone, there were 323 deaths due to fall of heavyweights from cranes out of 632 total crane-related deaths [2]. These types of deaths can be prevented by altering the workers to not to enter a particular region while the heavyweights are being lifted. So, we have developed a system which predicts the probable region of fall of heavyweights and indicates the region appropriately through a laser beam.

\section{PROBLEM STATEMENT}

To develop a system which can reduce the number of injuries and deaths due to unnoticed falls of heavyweights lifted by cranes. The device also shall intimate through laser light indication the safe zone near such heavyweight equipment. The workers or employees are expected to use that indication as the reference mark and to stay on or after that light indication to avoid the injuries and accidents. 


\section{EXISTING SOLUTIONS}

As one could easily understand the importance of such systems, scientists have started working on the solutions and they made reasonable progress too. But all the solutions available are not complete in many aspects. These are some of the existing solutions for the prevention and reduction of deaths due to crane accidents in industries.

Chae, S. solution uses RFID (Radio Frequency Identification) technology for prevention of collision accidents due to heavy equipment such as cranes and hydraulic excavators. They have designed a system which gets the proposed working area $\&$ its data using RFID technology. This data is used for the estimation of working areas which will be used for prevention of collision accidents. The main drawback of this solution is obtaining working area data through RFID technology involves huge cost factor \& processing power. [3]

Fang, Y. solution focuses mainly on the improvement of communication between the crane operators and ground personnel at the blind spots to decrease the accidents. In general, the collaboration between ground personnel and the crane operators is restricted and requires advanced communication techniques, like radios, to resolve the limited visibility issue. So, they have developed a solution which uses a virtual training environment with multiple participants in lifting operations. They used a 3D real-time immersive visualization interface where users can perform hands-on tasks such as directing blind lifts and operating cranes with safety hazards and geometry constraints. This solution only increases the ease of communicating between the ground personnel \& crane operator but there are many cases of crane accidents even when there is good communication between them. [4]

Bernold, L.E. solution is a crane monitoring system which is capable of warning an operator who enters into a danger zone and stores critical events information on an electronic device. It acts like a black box on an aeroplane, the storage device allows this information to be downloaded by a supervisor to assess how a particular crew "worked" the crane. This solution only provides information about the incidents and the data for analysis but doesn't prevent or reduce the deaths due to crane accidents. [5]

Unlike the above-mentioned solutions, the proposed system can predict the danger area inside which the lifted weight might fall without the use of any 3D visualization environment or RFID technology. This helps the ground personnel to understand the area outside which they have to stand and operate.

One can understand the existing solutions clearly from the below Table 2 and the features to be present in the proposed system as well be referred.
Table 2: Events resulting in mobile crane-related occupational injury deaths: United States [1]

\begin{tabular}{|l|c|c|c|c|c|}
\hline & $\begin{array}{l}\text { Danger } \\
\text { Area } \\
\text { Indicat } \\
\text { ion }\end{array}$ & $\begin{array}{l}\text { RFID } \\
\text { Techno } \\
\text { logy }\end{array}$ & $\begin{array}{l}\text { 3D } \\
\text { Visuali } \\
\text { sation }\end{array}$ & $\begin{array}{l}\text { Reduci } \\
\text { ng } \\
\text { deaths }\end{array}$ & Alerts \\
\hline Chae, S. & $\checkmark$ & $\checkmark$ & $\times$ & $\checkmark$ & $\checkmark$ \\
\hline Fang, Y. & $\times$ & $\times$ & $\checkmark$ & $\checkmark$ & $\times$ \\
\hline $\begin{array}{l}\text { Bernold, } \\
\text { L.E. }\end{array}$ & $\checkmark$ & $\times$ & $\times$ & $\times$ & $\checkmark$ \\
\hline $\begin{array}{l}\text { Proposed } \\
\text { system }\end{array}$ & $\checkmark$ & $\times$ & $\times$ & $\checkmark$ & $\checkmark$ \\
\hline
\end{tabular}

\section{ARCHITECTURE}

For the prototype purpose, we have simulated the crane heavy weight lifting action with the help of an iron stand. Our prototype consists of two parts i.e., transmitter and receiver which are placed on the same crane. The transmitter is to be placed near the weight lifting hook of the crane while the receiver part is to be placed near the laser rotation part of the crane. The transmitter part consists of gyro and ultrasonic sensors using which we get the oscillatory movement of the hanging weight and sends it to the receiver part. The receiver part consists of servo motors attached with laser modules, depending on the angle of tilt and oscillatory motion of the hanging weight, the servo motors are rotated accordingly to indicate the danger zone. One could understand the workflow of the proposed system by referring Figure. 1.

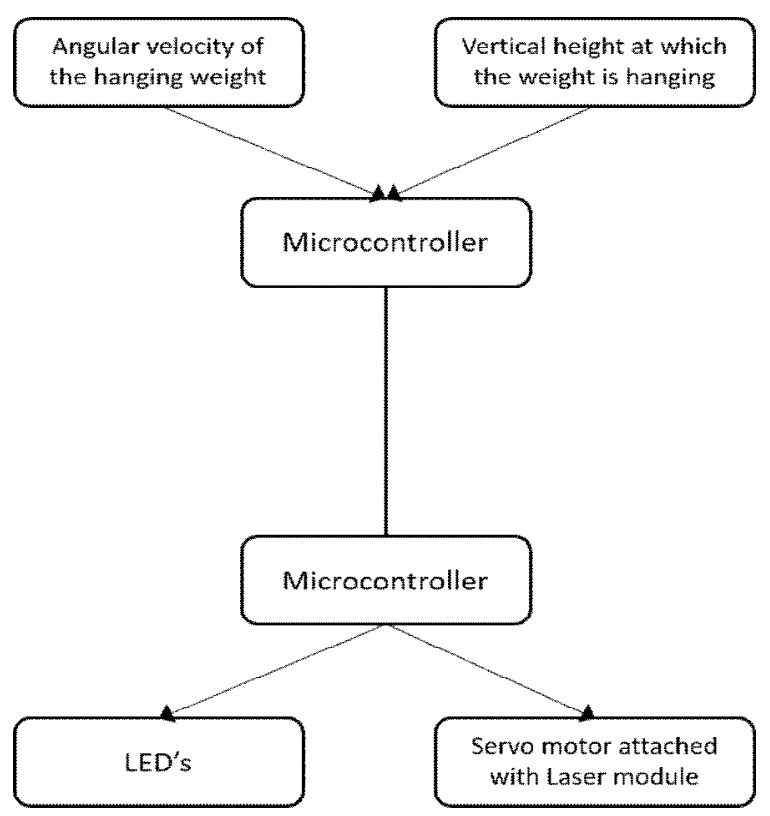

Figure 1: Work flow of the proposed System

The architecture of the proposed system is presented as Figure. 2. One can understand that the components used in this system are inexpensive and affordable as well. 


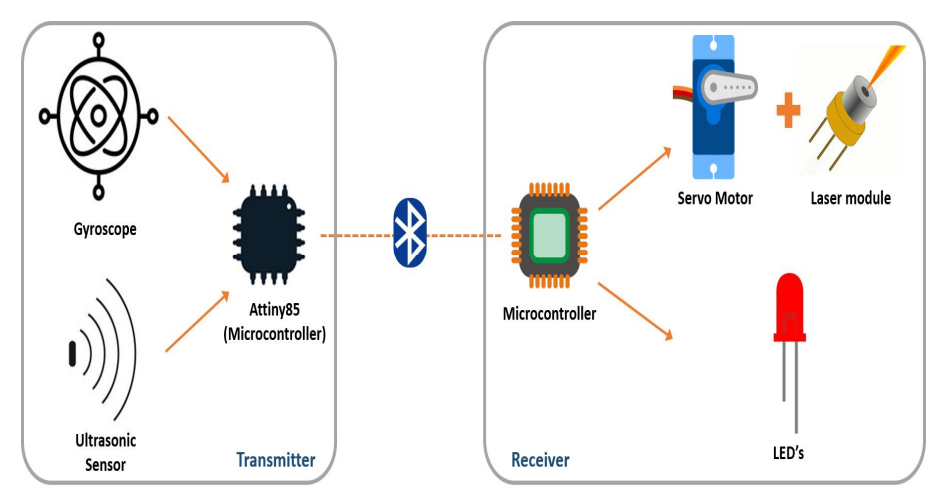

Figure 2: Architecture of the proposed system

\subsection{Design}

Initially, determine the maximum angle of tilt of the hanging weight in the $\mathrm{x}$-direction and then determine the maximum angle of tilt in the y-direction. If there is any rotation in the heavyweight while oscillating, then we observe variation in z-direction values. (Refer. Fig. 3)

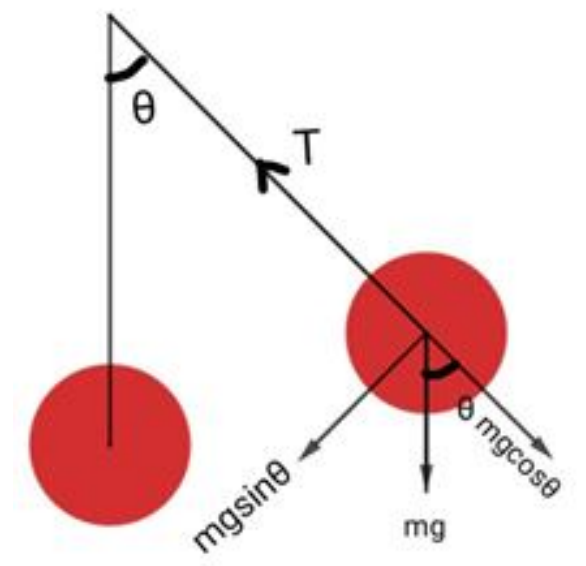

Figure 3: Architecture of the proposed system

Next step is to determine the height at which the hanging weight is oscillating. With the help of kinematic equations and vertical height at which the weight is oscillating, we get the horizontal projectile distance [6]. Combination of horizontal projectile distance and maximum angle of tilt gives us the radius of danger area in which the object might fall. (Refer Fig. 4)

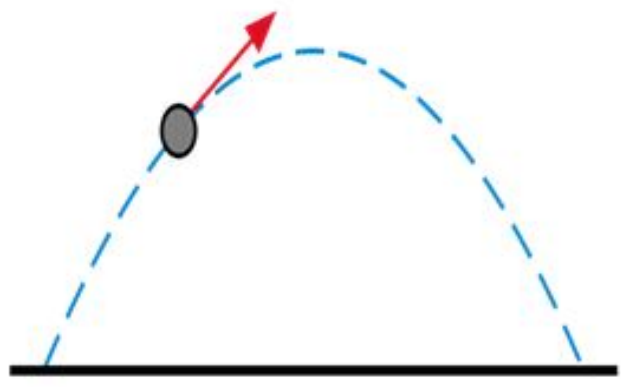

$\begin{array}{ll}v_{x}=v_{x 0}+a_{x} t & v_{y}=v_{y 0}+a_{y} t \\ x=x_{0}+v_{x 0} t+\frac{1}{2} a_{x} t^{2} & y=y_{0}+v_{y 0} t+\frac{1}{2} a_{y} t^{2} \\ v_{x}^{2}=v_{x 0}^{2}+2 a_{x}\left(x-x_{0}\right) & v_{y}^{2}=v_{y 0}^{2}+2 a_{y}\left(y-y_{0}\right)\end{array}$

Figure 4: Maximum angle of tilt of hanging weight

When the rope or wire is cut from the crane, at the leaving instance following parameters are defined:

Initial velocity in $\mathrm{x}$-direction, $\boldsymbol{V}_{\boldsymbol{x} \boldsymbol{0}}$

Final velocity in $\mathrm{x}$-direction, $\mathbf{V}_{\mathbf{x}}$

Acceleration in $\mathrm{x}$-direction, $\mathbf{a}_{\mathbf{x}}=0$

Horizontal projectile distance, $\boldsymbol{X}$

Initial velocity in y-direction, $\boldsymbol{V}_{\boldsymbol{y} \mathbf{0}}$

Final velocity in $\mathbf{y}$-direction, $\mathbf{v}_{\mathbf{y}}$

Acceleration in $\mathrm{y}$-direction, $\mathbf{a}_{\mathbf{y}}=\mathbf{g}$

Horizontal projectile distance, $\boldsymbol{Y}=\mathrm{H}$

Time of projectile, $\mathbf{t}$

In the $\mathrm{x}$-direction,

$\mathrm{V}_{\mathrm{x}}=\mathrm{V}_{\mathrm{x} \mathbf{0}}+(\mathbf{0}) * \mathrm{t}=\mathrm{V}_{\mathrm{x} \mathbf{0}}$ and

$\mathrm{V}_{\mathrm{x}}^{2}=\mathrm{V}_{\mathrm{x} 0}+2 *(0) *(\mathrm{X})=\mathrm{V}_{\mathrm{x} 0}^{2}$

$\mathbf{V}_{\mathbf{x}}=\mathbf{V}_{\mathbf{x} \mathbf{0}}$, the initial velocity is the same as the final velocity in $\mathrm{x}$-direction i.e, there is no change in $\mathrm{x}$-direction velocity throughout the projectile.

$\mathrm{X}=\mathrm{V}_{\mathrm{x} 0} * \mathrm{t}+\mathbf{0 . 5} *(0) * \mathrm{t}^{2}=\mathrm{V}_{\mathrm{x} 0} * \mathrm{t}$

$\mathbf{X}=\mathbf{V}_{\mathbf{x} \mathbf{0}} * \mathbf{t}$, Horizontal projectile distance is the velocity in $\mathrm{X}$-direction times total travel time of projectile.

We get the time of projectile $(\mathrm{t})$ from the $\mathrm{y}$-direction equations,

$\mathrm{V}_{\mathrm{y}}=\mathrm{V}_{\mathrm{y} 0}+\mathrm{g} * \mathrm{t} \rightarrow 1$

$\mathrm{V}_{\mathrm{y}}{ }^{2}=\mathrm{V}_{\mathrm{y} 0}+2 * \mathrm{~g} * \mathrm{H} \rightarrow 2$

$\mathrm{H}=\mathrm{V}_{\mathrm{y} 0} * \mathrm{t}+0.5 * \mathrm{~g} * \mathrm{t}^{2} \rightarrow 3$

By solving equations $1 \& 2$ or equation 3 alone, we get the time of projectile,

$\mathrm{t}=\frac{-v y 0+\sqrt{2 g H+V y 0^{2}}}{g}$

By substituting time of projectile, $\mathbf{t}$ in $\mathbf{X}=\mathbf{V}_{\mathbf{x} \mathbf{0}} * \mathbf{t}$, we get the horizontal projectile distance.

Horizontal projectile distance, $\mathrm{X}=\mathrm{V}_{\mathbf{x} 0} * \frac{-V y 0+\sqrt{2 g H+V y 0^{2}}}{g}$ 


\subsection{Transmitter}

In the transmitter part, we have an Ultrasonic sensor, Gyro (MPU-6050), Bluetooth (HC-05) modules. The Gyro sensor gives the angular velocity of the hanging object thereby we can detect the position, maximum angle of oscillation of the hanging weight [7]. After getting cut, the object flies off in projectile motion. For determining the distance of horizontal projectile, we need the height at which the object is hanging. We use the Ultrasonic sensor for determining the height at which the heavyweight is hanging from the ground. Entire sensor data is processed and sent via Bluetooth module by a small microcontroller called At-tiny 85.

At-tiny 85: It's a small size Arduino bootloader compatible microcontroller with only 5 Input/output (I/O) pins. It is used as a microcontroller in the transmitter part which makes the circuit small.

Gyro (MPU-6050): It is used for determining the angular velocity of the object in all the 3 directions on which it is placed.

Ultrasonic Sensor (HC-SR04): Ultrasonic sensor is primarily used for determining the distance of an object from the sensor based on the principle of sonar.

Bluetooth Module (HC-05): Bluetooth module is used for wireless communication between devices. Here we have used two Bluetooth modules one for the transmitter and another for the receiver. These Bluetooth modules are configured in a master-slave configuration, which pairs to each other for transmitting the data. [8].

One could have a look at the transmitter circuit in Fig. 5

followed by implementation in Fig. 6 in the form of prototype.

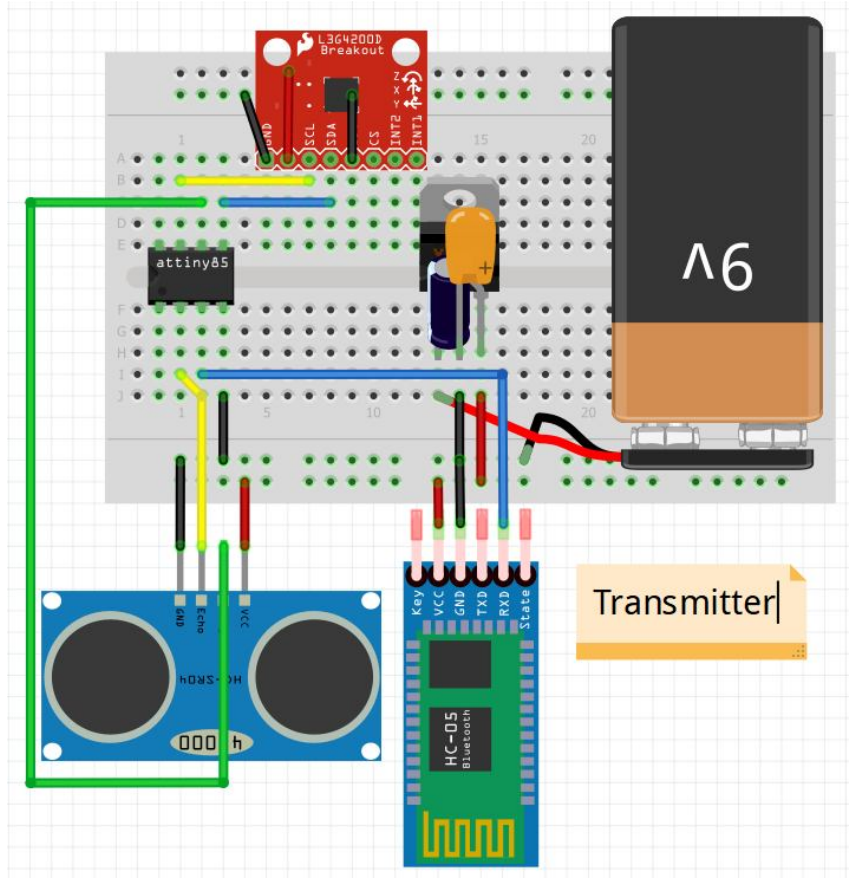

Figure 5: Transmitter Circuit of Prototype
We have used LM7805, 10uF capacitor and $1 \mathrm{uF}$ ceramic capacitor for reducing the $9 \mathrm{~V}$ battery voltage to $5 \mathrm{~V}$ in the transmitter circuit of our prototype.

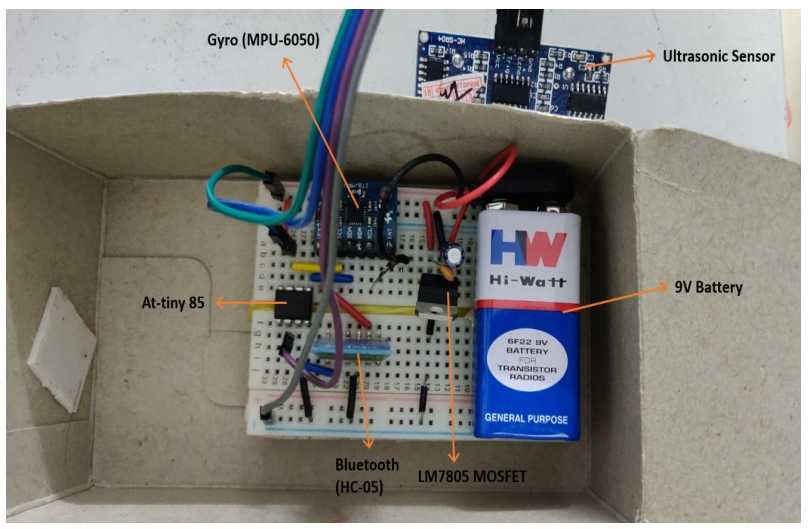

Figure 6: Transmitter Circuit of Prototype

The below Arduino code is burnt in Attiny85 microcontroller for transmitting the gyro and ultrasonic sensor data to the receiver.

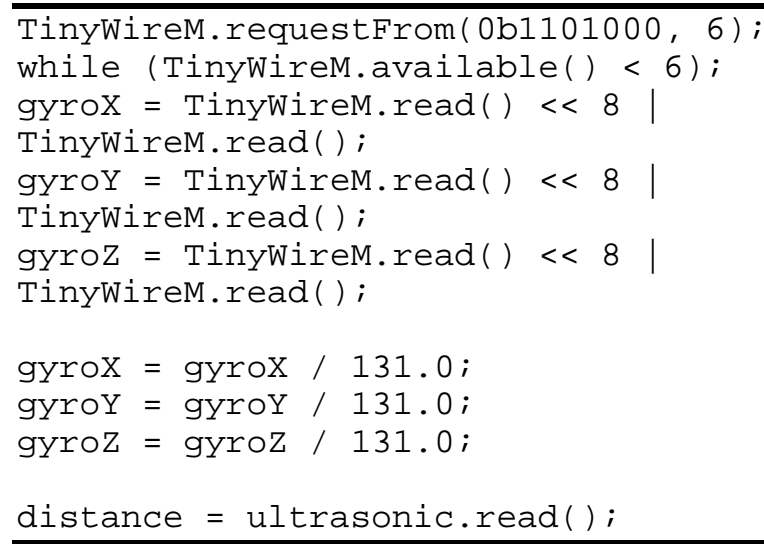

\subsection{Receiver}

In the receiver part, we have a Bluetooth module for receiving the gyro and ultrasonic data from the transmitter part. This data is sent into the microcontroller (Arduino Uno) for controlling the servo motor on which a laser module is attached. Three kinds of LED's are used (Green, White and Red) for indicating the intensity of oscillation. Red indicates, the oscillation of hanging weight is very big whereas white indicates the oscillations are in mid-range and green indicates the oscillations are in the permissible range. According to the range of oscillation appropriate danger location is indicated with the help of a laser.

Servo Motors: Servo motors are controlled by PWM pins. Servo motors can rotate to a particular angle depending on the input signal from the PWM pins. We can control the angle of rotation of servo motors depending on the range of oscillation and horizontal projectile distance. [9]

Laser Module: Similar to LED, laser modules project laser light on powering up the module. These are used for 
indicating the location pin-pointedly with the help of a single light beam.

Arduino Uno: Similar to Attiny85, Arduino Uno is also a microcontroller with many Input/output pins which can be used to control many sensors at a time. Here, it is used to control the servo motor with the help of its PWM pins and indicate the range of oscillation through an LED.

Iron Stand: For the prototype purpose, as we cannot test our system on a crane, we have created a simple oscillating system with the help of an Iron stand on which our prototype is demonstrated.

One could have a look at the receiver circuit in Fig. 7 followed by implementation in Fig. 8 in the form of prototype.

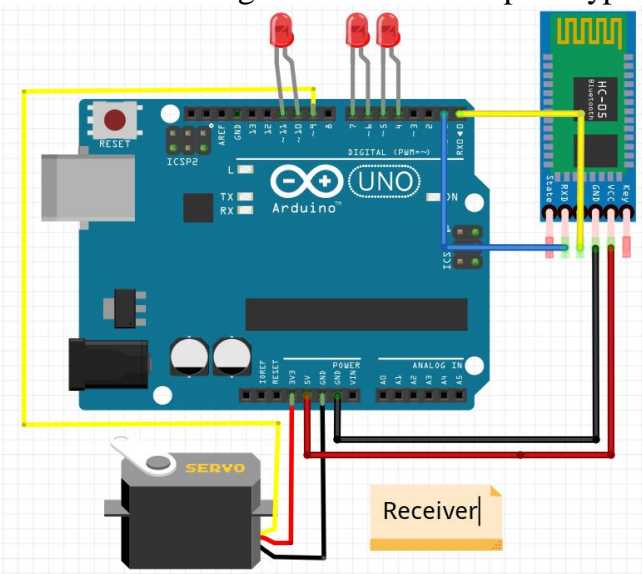

Figure 7: Receiver circuit of our Prototype

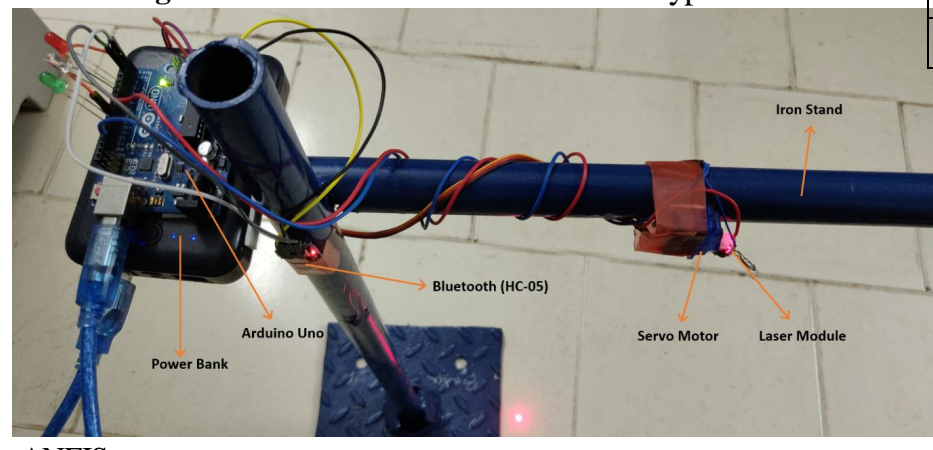

ANFIS

Figure 8: Receiver Prototype

The below Arduino code is burnt in Arduino Uno for controlling the angle of servo motor according to the oscillation and height at which the weight is hanging.

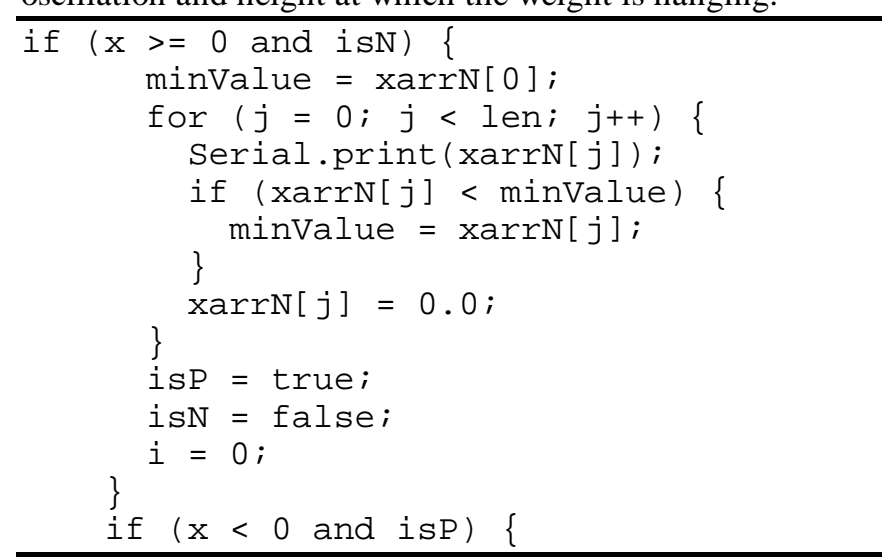

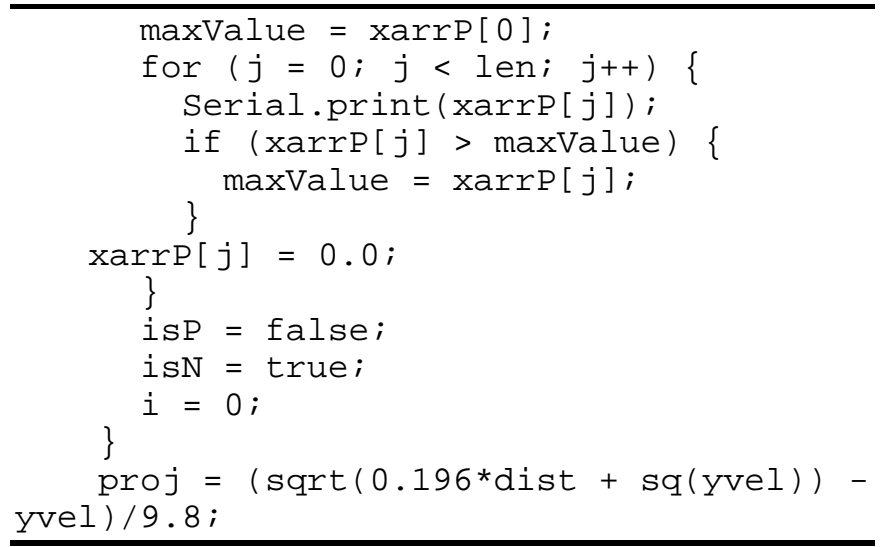

\section{COMPONENTS USED}

\begin{tabular}{|l|c|c|}
\hline \multicolumn{1}{|c|}{ Component Name } & Quantity & $\begin{array}{c}\text { Cost } \\
\text { (in \$) }\end{array}$ \\
\hline At-tiny 85 & 1 & 3 \\
\hline Gyro Sensor (MPU-6050) & 1 & 4 \\
\hline Ultrasonic Sensor (HC-SR04) & 1 & 2 \\
\hline Bluetooth Module (HC-05) & 2 & 9 \\
\hline Arduino Uno & 1 & 7 \\
\hline Servo Motor & 1 & 4 \\
\hline Laser Module & 1 & 1 \\
\hline LED's & 3 & 1 \\
\hline Iron Stand & 1 & 10 \\
\hline
\end{tabular}

\section{RESULTS}

Figure 9 shows the maximum angle of oscillation of the hanging weight in all three directions. Red line indicates the oscillation in the $\mathrm{x}$-direction. Initially, the angle of tilt is between -50 and 50 but it comes down to 0 with time. We can also observe, initially time taken for one oscillation is less but it increases with the number of oscillations. The green line indicates oscillation in the y-direction and the blue line indicates the oscillation in the $\mathrm{z}$-direction. As the blue line is not straight, there is rotation in the hanging weight while oscillating.

$-x-y-z$

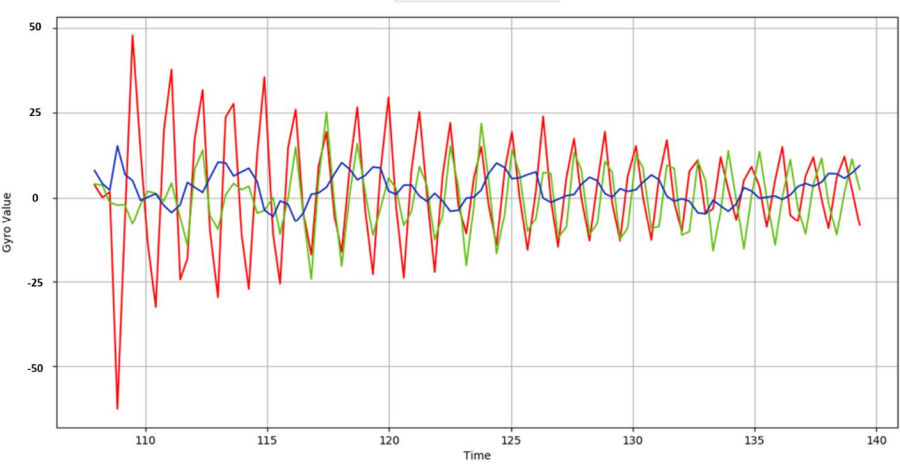

Figure 9: Hanging weight's gyro data plotted with time 


\section{Implementation Video:}

https://www.youtube.com/watch?v=NFMDcKM9w6U

The video shows the entire Implementation of our prototype in real-time. Here, we have used only one laser module which shows the radial end of the danger zone taking the hanging weight as the center.

Figure 10 shows the entire prototype along with receiver and transmitter part attached on the iron stand.

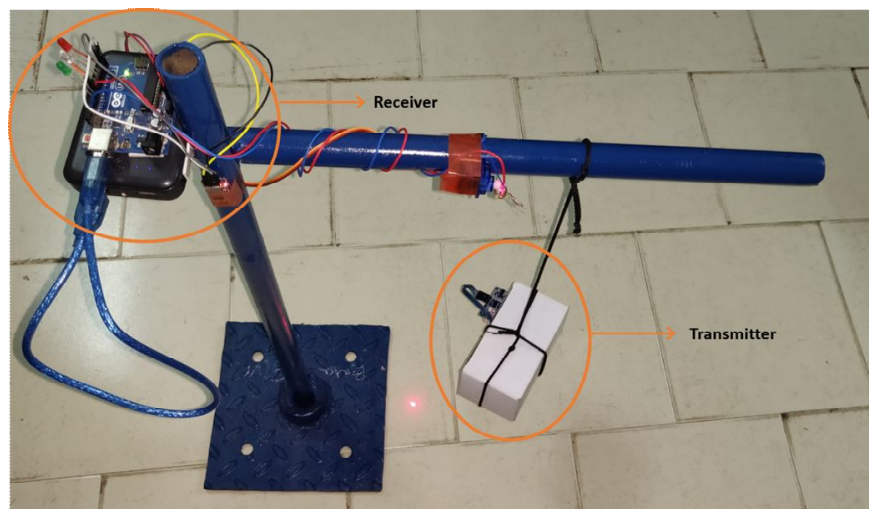

Figure 10: Complete Prototype

\section{CONCLUSION AND FUTURE ENHANCEMENTS}

The way IoT and sensors have been growing is very appreciable and we have exploited the same to build a product to solve one of the very important, regularly faced problems with cranes $[10,11,12,13,14]$. The main reason for these kinds of incidents is the lack of knowledge about the danger area under which the object might fall. Our system can be implemented in almost all industrial units for preventing the deaths, injuries due to the unnoticed heavy weight falls. The system needs enhancements to be done in aspects of accuracy of the sensors, communication between transmitter and receiver using low-cost transmission technology for implementing in real-time scenarios.

\section{REFERENCES}

[1] - NIOSH Alert | Preventing Worker Injuries and Deaths from Mobile Crane Tip-Over, Boom Collapse, and Uncontrolled Hoisted Loads.

https://www.craneaccidents.com/wp-content/themes/CraneA ccidents/pdf/stats/NIOSH-Alert-2006.pdf

[2] - Crane-Related Deaths in Construction and Recommendations for Their Prevention https://www.cpwr.com/research/completed/crane-related-dea ths-construction-and-recommendations-their-prevention [3] - Chae, S. and Yoshida, T., 2010. Application of RFID technology to prevention of collision accident with heavy equipment. Automation in construction, 19(3), pp.368-374.

https://doi.org/10.1016/j.autcon.2009.12.008
[4] - Fang, Y. and Teizer, J., 2014. A multi-user virtual 3D training environment to advance collaboration among crane operator and ground personnel in blind lifts. In Computing in Civil and Building Engineering (2014) (pp. 2071-2078). https://doi.org/10.1061/9780784413616.257

[5] - Bernold, L.E., Lorenc, S.J. and Luces, E., 1997. Intelligent technology for truck crane accident prevention. Journal of construction engineering and management, 123(3), pp.276-284.

[6] - Kinematics \& Projectile motion | https://www.khanacademy.org/science/physics/one-dimensio nal-motion/kinematic-formulas/a/what-are-the-kinematic-fo rmulas

[7] - Gyro sensors - How they work | https://www5.epsondevice.com/en/information/technical_inf o/gyro/

[8] - How to Configure and Pair Two HC-05 Bluetooth Modules as Master and Slave | AT Commands | https://howtomechatronics.com/tutorials/arduino/how-to-con figure-pair-two-hc-05-bluetooth-module-master-slave-comm ands/

[9] - Servo Motor Working |

https://circuitdigest.com/article/servo-motor-basics

[10]. Gayathri, Shriram K Vasudevan, "IoT based smart health monitoring of industrial standard motors - a novel approach", Indonesian Journal of Electrical Engineering and Informatics (IJEEI), Vol. 6, No. 4, December 2018, pp. 361 367, ISSN: 2089-3272, DOI: 10.11591/ijeei.v6i1.492

[11]. Aswath Gi, Shriram K Vasudevan, Sundaram RMD, "Emerging Security Concerns for Smart Vehicles and proposed IoT solutions, International Journal of Vehicle Autonomous Systems (IJVAS), Inderscience Publishers, Vol. 14, No. 2, 2018, PP. 107-133.

[12]. Abhishek SN, Shriram K Vasudevan, Ikram Shah, "An Innovative Solution for prevention of reverse flow of blood in IV set (Intravenous set) using Embedded Systems" International Journal of Medical Engineering and Informatics, ISSN online: 1755-0661 ISSN print: 1755-0653, Inderscience Publishers, Vol. 11, No. 4, 2019. PP 357 -367. https://doi.org/10.1504/IJMEI.2019.104966

[13] S. Mahalakshmi and Dr.R.Latha, Artificial Intelligence with the Internet of Things on Healthcare systems: A Survey, PP - 2847 - 2854, Volume 8 No. 6 (2019), International Journal of Advanced Trends in Computer Science and Engineering https://doi.org/10.30534/ijatcse/2019/27862019

[14] Dr. Omar Radhi Alzuobi , Dr. Bilal Radhi Alzuobi, Dr. Hamza A .Ibrahim and Marwan A. Al-Namari, Developing the Security and Protection of the Electronic Passport, PP 2993 - 2997, Volume 8 No. 6 (2019), International Journal of Advanced Trends in Computer Science and Engineering https://doi.org/10.30534/ijatcse/2019/52862019 